\title{
RESISTENCIA Y DEGRADACIÓN DE ARSÉNICO POR LA COMUNIDAD BACTERIANA DE LAS AGUAS DEL RÍO MAURE-TACNA, PERÚ
}

\author{
Responsable: MSc.Silvia Liliana Ara Rojas \\ Miembros : MSc. Angela Choque Miranda \\ Ing. Edgardo Avendaño Cáceres
}

\section{RESUMEN}

Para determinar la población bacteriana autóctona del río Maure (Perú) tolerante o que utiliza el arsénico (As) y que en un futuro podrían emplearse en procesos de biorremediación, se realizaron seis muestreos entre agosto y octubre de 2007, aislándose dieciocho (18) morfotipos coloniales con una sola morfología celular: bacilos Gram positivos, tolerantes a diferentes concentraciones de As (arsenito de sodio:100, $120,200,400$ y $600 \mathrm{mg} / \mathrm{mL}$ ). Cuatro de los morfotipos: $M_{3}, M_{6}, M A_{9}$ y $M_{10}$ crecieron quimioautotróficamente, en medio $\mathrm{M} 9+\mathrm{NaAsO}_{2}$ $(600 \mu \mathrm{g} / \mathrm{mL})$ a diferentes velocidades por lo que se trataria de especies diferentes. Para el Perú este constituiria un primer reporte de bacterias acuáticas autóctonas que utilizan As como fuente de energia.

\begin{abstract}
To determine the native bacterial population of the river Maure of Perú tolerant or using arsenic and that could be used in future processes for bioremediation, six samplings were carried out between Augusts to October 2007. Isolating, eighteen (18) morphotypes colonial with a single cell morphology: grampositive bacilli, tolerant to different concentrations of $\mathrm{NaAsO}_{2}(100,120,200$, 400 and $600 \mathrm{mg} / \mathrm{mL}$ ). Four of the morphotypes; $\mathrm{MA}_{3}, \mathrm{MA}_{6}, \mathrm{MA}_{9}$ and $\mathrm{MA}_{10}$ grew chemoautotrophic, under aerobic conditions and darkness, in media $\mathrm{M} 9+\mathrm{NaAsO}_{2}(600 \mu \mathrm{g} / \mathrm{mL})$ at different speeds so it would be different species. For Perú, this is a first report of indigenous aquatic bacteria using arsenic (As) as a source of energy.
\end{abstract}

\section{INTRODUCCIÓN}

La contaminación del ambiente con metales tóxicos y radionúcleos surge como resultado de actividades humanas, principalmente industriales; sin embargo, fuentes como la agricultura y la eliminación de residuos también contribuyen. Estos contaminantes son descargados en la atmósfera y en los ambientes acuáticos y terrestres, principalmente como solutos o partículas y pueden alcanzar concentraciones elevadas, especialmente cerca del sitio de descarga. Los efectos de los metales sobre el funcionamiento de los ecosistemas varian considerablemente y son de importancia económica y de salud pública. Entre los mecanismos moleculares que determinan la toxicidad de los metales pesados se encuentran: 1. El desplazamiento de iones metálicos esenciales de biomoléculas y bloqueo de sus grupos funcionales, 2. modificación de la conformación activa de biomoléculas, especialmente enzimas y polinucleótidos, 3 . ruptura de la integridad de biomoléculas y 4 . modificación de otros agentes biológicamente activos (Ochiai, 1987).

El arsénico (As) y el plomo ( $\mathrm{Pb}$ ) son tóxicos inorgánicos que comúnmente contaminan ambientes. El arsénico, como otros elementos, está sujeto a transformaciones microbianas. La reducción y metilación por bacterias puede formar arsinas gaseosas, generando la volatilización del arsénico o la mineralización de compuestos orgánicos de arsénico a compuestos inorgánicos. Estas transformaciones influyen en el ciclo del arsénico y en su acumulación en suelo y agua. La acumulación del arsénico revierte gran importancia no sólo por su toxicidad, sino también por su potencialidad para contaminar fuentes de agua subterránea.

En el Perú, varios afluentes presentan contaminación con metales pesados como el arsénico. En Tacna, todos los afluentes presentan este problema. De allíla necesidad de generar mecanismos que permitan su descontaminación y, por ende, la utilización de esta agua para el consumo de la población. Esto se hace primordial para nuestra región, pues la demanda hídrica es superior a la oferta actual y son los ríos como el Maure, Uchusuma, Locumba, entre otros, que forman parte del recurso hidrico de la región, los que podrian permitir acortar esta distancia entre la demanda y la oferta. Pero las aguas de estos ríos presentan arsénico que en muchos casos, como por ejemplo el del río Maure, su concentración excede a la permisible. Por ello, el presente proyecto se planteó como problema el determinar la comunidad bacteriana autóctona del río Maure (uno de los de mayor 
contaminación con metales tóxicos) que es resistente o que utiliza el arsénico y que en un futuro podrian emplearse en procesos de biorremediación de sus aguas.

\section{MATERIALY MÉTODOS}

Recolección de muestras de agua:Las muestras de agua del rio se colectaron en botellas de vidrio con tapa rosca de $1 \mathrm{~L}$ de capacidad, previamente lavadas con $\mathrm{HCl} 0,1 \mathrm{~N}$, enjuagadas con agua destilada y esterilizadas por autoclavado estándar. En cada muestreo se tomaron tres muestras contracorriente: una del borde del afluente, otra de la superficie del agua que discurre a $2 \mathrm{~m}$ del borde y otra a $10 \mathrm{~cm}$ de profundidad de esta última zona. Dichas muestras fueron colocadas a $4^{\circ} \mathrm{C}$ en una caja conservadora con bolsas de hielo seco para su transporte al laboratorio de Microbiologia de la Universidad Nacional Jorge Basadre en Tacna, donde se procesaron.

Cuantificación de arsénico:Se realizó tanto en las muestras de agua como en las muestras de cultivo de la etapa de utilización de As como fuente de energía. Esta cuantificación se hizo utilizando el Arsenic Test Kit de HACH Company World Headquarters, con un rango de detección de 0 a 500 ppm (mg/L) de arsénico.

Recuento del número total de bacterias mesófilas viables:Se realizó por el método de diseminación en placa, usando como medio de crecimiento Agar Mueller Hinton suplementado con Trifenil tetrazolio cloruro (TTC) como indicador de óxido reducción. Cada muestra se trabajó por triplicado, endiluciones de 10 y 10 la incubación fue $25^{\circ} \mathrm{C}$ por 3 a 7 dias.

\begin{abstract}
Aislamiento de bacterias resistentes a Arsénico (Zeliborg et al, 1987): Para el aislamiento de bacterias resistentes a arsénico se trabajó con las mismas diluciones usadas en la etapa anterior, a partir de las cuales se tomó 0,1 $\mathrm{mL}$ de cada tubo para su siembra por diseminación en placas con medio de prueba consistente en Agar Mueller Hinton + TTC con diferentes concentraciones de arsénico: 200, 500,1000 y $2000 \mathrm{ug} / \mathrm{mL}$ de As bajo la forma de arsenito de sodio. Cada prueba de resistencia se realizó por triplicado, se incubó a $25^{\circ} \mathrm{C}$ hasta por 10 dias y se determinó el número de UFC resistentes a As $(\mathrm{mg} / \mathrm{mL})$.
\end{abstract}

Obtención de cultivos puro: A partir de las placas con diferentes concentraciones de arsénico se aislaron cultivos puros de cada morfotipo colonial, en tubos de ensayo con medio Mueller Hinton y arsenito de sodio $(200 \mu \mathrm{g} / \mathrm{mL})$. Estos fueron incubados a $25^{\circ} \mathrm{C}$ hasta el desarrollo del cultivo y conservados en refrigeración.

Identificación preliminar de especies:La tipificación de las cepas aisladas se hizo sobre la base de caracteres morfológicos (coloración
Gram) y fisiológicos (pruebas de tolerancia y utilización de arsénico como única fuente de energia).

Prueba de utilización de arsénico como única fuente de energia:Cada cultivo puro fue transferido a placas de medio M9 suplementadas con arsenito de sodio a una concentración de 600 $\mu \mathrm{g} / \mathrm{mL}$ e incubadas a $25^{\circ} \mathrm{C}$ por 10 dias. Para comprobación de resultados y cualificación del uso del As en un lapso de tiempo, las cepas con desarrollo en esta etapa fueron resembradas en $50 \mathrm{~mL}$ de medio líquido M9 con arsenito de sodio $(600 \mu \mathrm{g} / \mathrm{mL})$ con una turbidez inicial equivalente al tubo 0,5 de la escala de Mac Farland $\left(10^{8}\right.$ UFC/mL) que se incubaron en aerobiosis, $25^{\circ} \mathrm{C}$ y en oscuridad por 10 dias. Aquellas que desarrollaron fueron conservadas a $-20{ }^{\circ} \mathrm{C}$ para un posterior trabajo de investigación que se abocará a identificarlas fisiológica $y / o$ genéticamente y a determinar la velocidad a la cual degradan arsénico.

Procesamiento y análisis de los datos: Con los datos de recuento total de bacterias y de bacterias resistentes a arsénico se calculó el porcentaje de células resistentes a cada concentración de As empleando la siguiente ecuación:

$\%$ cel resistente $=\frac{C F U / m L \text { en Mueller } H \text { int on con } A s}{C F U / m L \text { en Mueller } H \text { int } o n} \times 100$

\section{RESULTADOS}

Se realizaron en total seis muestreos de agua del rio Maure que presentaron arsénico (As) en concentraciones entre $0,98 \mathrm{a} 0,190 \mathrm{mg} / \mathrm{mL}$. Estas muestras tuvieron recuentos de bacterias mesófilas viables del orden de $10^{3} \mathrm{UFC} / \mathrm{mL}$ que a su vez incluian bacterias tolerantes al arsénico que representaron de 0,1 a $10 \%$ de la población (Tabla 1).

De las colonias que se desarrollaron en las placas con arsénico se aislaron dieciocho (18) morfotipos codificados con las siglas MA y los subindices del 1 al 18; de los cuales el 100\% fueron bacilos Gram positivos con crecimiento en medio Mueller Hinton con As en concentraciones menores o iguales a $200 \mu \mathrm{g} / \mathrm{mL}$, pero que a concentraciones mayores su comportamiento fue diferente. Nueve de ellos (50\%) se desarrollaron en la concentración más alta $(600 \mu \mathrm{g} / \mathrm{mL})$ y sólo un $22 \%$ crecieron en medio mínimo M9 (sólido) suplementado con As como única fuente de energía (Tabla 2). Los cuatro morfotipos $\mathrm{MA}_{3}$, $M A_{5}, M_{9}$ y $M A_{10}$ fueron resembrados en medio M9 sin agar (medio líquido) e incubados en oscuridad a $25^{\circ} \mathrm{C}$ y agitación constante $(120 \mathrm{rpm})$ por 10 dias para confirmar su desarrollo utilizando como única fuente de energia el As contenido en el medio de cultivo. Tomándose como resultado positivo el desarrollo o aumento de la turbidez del medio de cultivo. Las cuatro cepas dieron positivo a esta prueba, pero con 
diferentes intensidades de crecimiento en el tiempo de incubación. Los cultivos presentaron una turbidez final equivalente a los tubos $2\left(\mathrm{MA}_{3}\right.$, $\mathrm{MA}_{6}$ y $\left.\mathrm{MA}_{9}\right)$ y $5\left(\mathrm{MA}_{10}\right)$ de la escala de Mac Farland que corresponden a una concentración de $6 \times 10^{8}$ y $1,5 \times 10^{9}$ UFC/mL respectivamente (Figura 1).

Tabla 1. Recuento de bacterias mesófilas viables y bacterias tolerantes a cinco c o n c e n t r c i o n e s d e arsénico presentes en las muestras de agua del río Maure colectadas entre agosto a octubre del

\begin{tabular}{|ccccccc|}
\hline $\begin{array}{c}\text { Número de } \\
\text { Muestreo }\end{array}$ & TRBMV (10) & \multicolumn{5}{c|}{ Recuento de tolerantes al As ( g/mL) $\times 10$} \\
\hline I & & 120 & 160 & 200 & 400 & 600 \\
II & 9 & 90 & 30 & 20 & 30 & 5 \\
III & 7 & 60 & 10 & 20 & 7 & 1 \\
IV & 5 & 100 & 20 & 20 & 4 & 1 \\
V & 6 & 100 & 33 & 22 & 33 & 6 \\
VI & 8 & 86 & 14 & 29 & 10 & 1 \\
\hline
\end{tabular}

TRBMV = recuento total de bacterias mesófilas viables

Tabla 2. Caracterización morfológica y fisiológica de dieciocho morfotipos bacterianos aislados de muestras del rio Maure obtenidas entre agosto a octubre del 2007.

\begin{tabular}{|c|c|c|c|c|c|c|c|c|c|c|}
\hline Cepa & Morto & ogia & Reacción & a Gram & & & 5 Ims & (mL) & & $M 9+A_{5}$ \\
\hline & $\operatorname{coco}$ & bacilo & positiva & negativa & 100 & 160 & 200 & 400 & 600 & $(600 \mathrm{\mu g} / \mathrm{mL})$ \\
\hline $\mathrm{MA}_{1}$ & $\cdot$ & + & $\cdot$ & + & + & + & + & + & + & 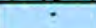 \\
\hline$M A_{2}$ & - & + & - & + & + & + & + & + & + & - \\
\hline$M A_{0}$ & - & + & - & + & + & + & + & + & + & + \\
\hline MA & - & + & - & + & + & + & + & + & + & - \\
\hline$M A_{5}$ & . & + & . & + & + & + & - & + & + & - \\
\hline MA. & - & + & - & + & + & + & + & + & + & + \\
\hline $\mathrm{MA}_{7}$ & - & + & . & + & + & + & . & + & + & - \\
\hline$M A_{6}$ & - & + & - & + & + & + & + & + & - & - \\
\hline$M A_{0}$ & - & + & . & + & + & + & + & + & - & + \\
\hline $\mathrm{MA}_{10}$ & - & + & - & + & + & + & + & + & - & + \\
\hline $\mathrm{MA}_{11}$ & - & + & . & + & + & + & + & + & + & - \\
\hline $\mathrm{MA}_{12}$ & - & + & - & + & + & + & + & + & + & - \\
\hline$M A_{13}$ & - & + & - & + & + & + & + & + & - & .. \\
\hline$M A_{14}$ & - & + & - & + & + & + & + & - & - & - \\
\hline$M_{145}$ & - & + & - & + & + & + & . & - & - & - \\
\hline $\mathrm{MA}_{16}$ & - & + & - & + & + & + & - & - & - & - \\
\hline$M_{17}$ & - & + & - & + & + & + & - & - & - & - \\
\hline $\mathrm{MA}_{10}$ & & 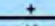 & & & + & & & & & \\
\hline Total & 0 & 18 & 0 & 18 & 18 & 18 & 13 & 13 & 9 & 4 \\
\hline$\%$ & 0 & 100 & 0 & 100 & 100 & 100 & 72 & 72 & 50 & 22 \\
\hline
\end{tabular}

Figura 1: Cultivo en medio $\mathrm{Mg}+\mathrm{NaAsO}_{2}(600 \mathrm{~g} / \mathrm{mL})$ de los morfotipos $\mathrm{Ma}_{3}$ y $\mathrm{Ma}_{10}$ en el día $1(\mathrm{~A})$ y 10 (B) del período de incubación.

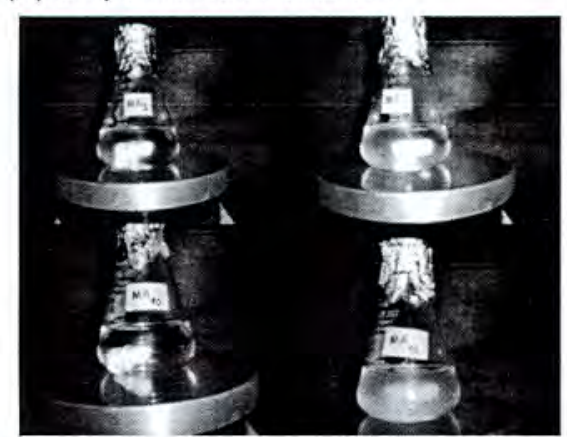

\section{DISCUSION}

La flora bacteriana mesófila aerobia del Maure fue abundante al obtenerse recuentos del orden de $10^{3} \mathrm{UFC} / \mathrm{mL}$; de los cuales aproximadamente $10^{2} \mathrm{UFC} / \mathrm{mL}$ correspondieron a bacterias capaces de tolerar concentraciones de arsénito de hasta $600 \mu \mathrm{g} / \mathrm{mL}$ (Tabla 1). Esto se deberia a un proceso de especiación por el largo periodo de tiempo que las aguas de este rio han contenido arsénico proveniente de fuentes geogénicas. Arsénico que se encontraría bajo la forma de arsenito o arsenato como lo señalan Bentley y Chansen (2002), quienes establecieron que las aguas de zonas geotermales, como aquellas por donde discurre el río Maure, contienen estos tipos de arsénico.

Los dieciocho morfotipos coloniales, tolerantes a arsenito, microscópicamente correspondieron a una única morfología: bacilos Gram positivos con diverso grado de tolerancia a diferentes concentraciones del metal pesado de prueba. De estos morfotipos sólo cuatro evidenciaron crecimiento quimioautotrófico con arsenito de sodio como fuente de energía al desarrollar bajo condiciones aerobias y en oscuridad en medio M9 suplementado con arsenito de sodio.

Uno de los principales problemas del arsénico (As) es que no puede ser biodegradado, pero los microorganismos como las bacterias pueden interactuar con él transformándolo por cambios en su estado de oxidación; lo que influye en forma drástica en la movilidad de este contaminante, pudiendo favorecer su eliminación. Las principales transformaciones pueden ser directas, por medio de cambios en el estado de valencia cuando actúan como donantes o receptores de electrones, e indirectas, por medio de agentes oxidantes y reductores producidos por los microorganismos y que son responsables de cambios en el $\mathrm{pH}$ y del potencial redox (Cervantes y col., McCullough et al, 1999). Dada la composición del medio de prueba, las cuatro cepas aisladas, $\mathrm{MA}_{3}, \mathrm{MA}_{6}, \mathrm{MA}_{9}$ y $\mathrm{Ma}_{10}$, tendrian la capacidad de transformar arsenito de sodio de manera directa.

La bacteria Pseudomonas arsenitoxidanses era el único organismo conocido que gana energia en presencia de arsenito. Este organismo tiene la habilidad de crecer quimiolitoautotróficamente con arsenito, oxígeno y dióxido de carbono. Pero Santini y colaboradores (2000) han reportado el aislamiento (de relaves de minas de oro en el norte de Australia) de una alfa-Proteobacteria del grupo Agrobacterium/Rhizobium que también crece quimiolitoautotróficamente con arsenito. Ambos reportes corresponden a bacterias bacilares Gram negativas.Para el Perú, no se cuenta con reportes de especies que utilicen arsenito y los morfotipos aislados en este trabajo corresponderían a un primer informe de bacterias aerobias Gram positivas con potencial biorremediador de arsenito. Bacterias Gram positivas pertenecientes a los géneros Staphylococcus, Rhodococcus y Bacillus han sido empleadas para biorremediar ambientes contaminados con metales pesados como el Cadmio (Adeniji, 2004; Connor et al., 1996). Los dos últimos géneros corresponden a formas bacilares y, por ende, las cepas $\mathrm{MA}_{3}, \mathrm{MA}_{6}, \mathrm{MA}_{9} \mathrm{y}$ $M A_{10}$ podrian estar relacionadas con ellos. Estas cepas corresponderian a cuatro especies 
diferentes con una misma morfología celular, dado que tuvieron comportamientos diferentes en cuanto a su velocidad de crecimiento en M9 con arsenito de sodio $y$, por ende, diferente velocidad de utilización del arsenito. De los cuatro morfotipos, $M_{10}$ fue el más eficiente al alcanzar una turbidez final (luego de 10 días de incubación) de $1,5 \times 10^{9} \mathrm{UFC} / \mathrm{mL}$ (tubo 5 de Mac Farland). Quedando pendiente la determinación cuantitativa del uso de arsénico por parte de los cultivos. Esto debido a que el kit de cuantificación que usamos no permitió reproductibilidad de resultados al usar como muestra el medio de cultivo prefiltrado con membrana de 0,22 um de diámetro de poro.

\section{CONCLUSIONES}

Según los resultados obtenidos en este trabajo, podemos concluir que:

1.Las aguas del rio Maure son hábitat de una importante población bacteriana tolerante a elevadas concentraciones de arsénico.

2.La flora mesófila de las aguas del río Maure incluyen a bacterias capaces de utilizar el arsénico bajo la forma de arsenito como donador de electrones. Las cepas $\mathrm{MA}_{3}, \mathrm{Ma}_{6}, \mathrm{MA}_{9}$ y $\mathrm{MA}_{10}$ aisladas son especies bacilares Gram positivas diferentes que pueden desarrollar quimioautotróficamente en medios con arsenito de sodio como fuente de energia.

\section{RECOMENDACIONES}

Ampliar el estudio, realizandolo para los demás ríos de la región

Establecer la tasa de degradación de arsénico de cada una de las cepas que usan este compuesto como fuente de energía

Otimizar el proceso de degradación (crecimiento en agua con arsénico) de las cepas degradadoras, a fin de usarlas en procesos de biorremediación In Situ.

\section{BIBLIOGRAFIAA}

Adeniji, A. 2004. Bioremediation of Arsenic, Chromium, Lead, and Mercury. National Network of Environmental Management Studies Fellow for U.S. Environmental Protection Agency Office of Solid Waste and Emergency Response Technology Innovation Office Washington, DC.

Bentley, R. and T.G. Chasteen. 2002. 'Microbial Methylation of Metalloids: Arsenic, Antimony, and Bismuth. Microbiol. And Molec." Biol. Rev. 66(2): 250271.

Cervantes, C.; A:E: Espino-Saldaña, F. AcevedoAguilar, I.L. León-Rodriguez, M.E. Rivera-Cano, M. Avila-Rodriguez, K. Wróbel-Kaczmarczyk, K. Wróbel-Azada, J.F. Gutierrez-Corona, J.S. Rodríguez-Zavala y R. Montero-Sánchez. 2006. "Interacciones microbianas con metales pesados." Rev. Lat. de Microbiol. 48(2): 203210.

Connor, D., P. Landin, E. Mellor, and C. O'Donovan. 1996. The Microbiology of In Situ Bioremediation.Http://www.cee.vt.edu/program areas/environmental/teach/gwprimer/biorem.ht $\underline{\mathrm{ml}}$

McCullough, J., Hazen, T.C., Benson, S.M., Metting, F.B., and Palmisano, A.C. 1999. Bioremediation of Metals and Radionucleids.. What it is and how it works. Office of Biological and Environmental Research of the U.S. Department of Energy's Office of Science. NABIR primer LBNL-42595. Http://www.lbl.gov/NABIR/primer

Ochiai, E. I. 1987. General principles of biochemistry. of the elements. Plenum Press, New York, 648 p.p.

Santini J.M., I. Lindsay. R.Sly, D. Schnagl, and J.M. Macy.2000. A New Chemolithoautotrophic Arsenite-Oxidizing Bacterium Isolated from a Gold Mine: Phylogenetic, Physiological, and Preliminary Biochemical Studies. Applied and Environmental Microbiology. 6(1): 92-97.

Zelibor, J.L.; M.W. Doughten, D.J. Grimes, and R.R. Colwell. 1987. Testing for Bacterial Resistance to Arsenic in Monitoring Well Water by the Direct Viable Counting Method Appl. Environm. Microbio. 53(12): 2929-2934 